\title{
Deficits in Verbal Working Memory among College Students with Attention- Deficit/Hyperactivity Disorder Traits: An Event-related Potential Study
}

\author{
Seulki Kim, Myung-Sun Kim \\ Department of Psychology, Sungshin Women's University, Seoul, Korea
}

\begin{abstract}
Objective: This study investigated verbal working memory in college students with traits of attention-deficit/hyperactivity disorder (ADHD) using event-related potentials and the 2-back task.

Methods: Based on scores on the Adult ADHD Self-Report Scale and Conners' Adult ADHD Rating Scale, participants were assigned to the normal control $(n=28)$ or ADHD-trait $(n=29)$ group. The 2-back task, which was administered to evaluate working memory, consists of a congruent condition, under which the current stimulus is the same as the one presented two trials earlier, and an incongruent condition, under which the current stimulus is not the same as the one presented two trials earlier. The numbers 1, 2, 3, and 4 were used as stimuli.

Results: On the 2-back task, the ADHD-trait group committed significantly more errors in response to congruent stimuli and showed a smaller P300 amplitude than did the control group.

Conclusion: These results indicate that college students with ADHD traits have deficits in verbal working memory, possibly due to difficulties in memory updating or attentional allocation.
\end{abstract}

KEY WORDS: Attention-deficit/hyperactivity disorder; Event-related potentials; 2-back task; P300; Verbal working memory.

\section{INTRODUCTION}

Attention-deficit/hyperactivity disorder (ADHD) is a neurodevelopmental disorder characterized by inattention, hyperactivity, and impulsivity; some ADHD symptoms are known to persist into adulthood. ${ }^{1-4)}$ A variety of cognitive deficits are observed in adult patients with $\mathrm{ADHD}^{5,6)}$; in particular, deficits in working memory have been consistently reported. ${ }^{7-9)}$ For example, adults patients with ADHD exhibit significantly poorer performances on the working memory tests, such as digit-span test, ${ }^{10)}$ letternumber-sequencing test, ${ }^{11)}$ and working memory indexes of the Wechsler Adult Intelligence Scale-III and the Wechsler Memory Scale-III ${ }^{12)}$ than did healthy controls.

Working memory, defined as the online maintenance and manipulation of information for a few seconds, involves a central executive, a phonological loop, and a visuospatial sketchpad. ${ }^{13)}$ The central executive is involved

\footnotetext{
Received: June 12, 2015 / Revised: August 8, 2015

Accepted: August 18, 2015

Address for correspondence: Myung-Sun Kim, PhD Department of Psychology, Sungshin Women's University, 2, Bomun-ro 34da-gil, Seongbuk-gu, Seoul 02844, Korea Tel: +82-2-920-7592, Fax: +82-2-920-2040 E-mail: kimms@sungshin.ac.kr
}

in information integration and attentional allocation, and the phonological loop and visuospatial sketchpad are involved in processing verbal and visuospatial information, respectively. Working memory affects higher cognitive functions, including inhibition and reasoning or problemsolving. ${ }^{14,15)}$ In particular, working memory is related to inattention, which is one of the core ADHD symptoms. ${ }^{16-18)}$

The $n$-back task requires the participant to judge whether a currently presented stimulus is the same as the one presented $n$ trials earlier. ${ }^{19,20)}$ The $n$-back task is known to be useful for the measurement of working memory, as this task evaluates not only the maintenance and retrieval of information but also its monitoring and updating (i.e., the manipulation of information). ${ }^{21-23)}$ Previous studies have reported that adult patients with ADHD showed significantly longer response times and lower accuracy rates on the $n$-back task than did normal controls, ${ }^{24,25)}$ indicating that adult patients with ADHD have deficits in working memory.

Neuroimaging studies investigating the cerebral mechanisms underlying verbal working memory have identified increased activation in the prefrontal and parietal cortices during the $n$-back task. ${ }^{26-29)}$ Specifically, it has been reported that the dorsal prefrontal cortex is involved in mani-

(c) This is an Open-Access article distributed under the terms of the Creative Commons Attribution Non-Commercial License (http://creativecommons.org/licenses/by-nc/4.0) which permits unrestricted non-commercial use, distribution, and reproduction in any medium, provided the original work is properly cited. 
pulating information, whereas the posterior parietal cortex is involved in maintaining and updating information. ${ }^{30-33)}$ Adult patients with ADHD exhibited significantly reduced activation in the prefrontal and parietal cortices than did normal controls while performing a verbal working memory task. ${ }^{24,25,34-36)}$ These results indicate that the deficits in verbal working memory observed in adult patients with ADHD are related to dysfunctions in the prefrontal and parietal cortices.

Although neuroimaging studies have identified the brain regions involved in verbal working memory, these studies have provided only limited information about the temporal course of activation of the brain regions involved in the execution of verbal working memory. However, event-related potentials (ERPs) have been widely used to investigate cognitive functions, including working memory, due to the high temporal resolution associated with this technique. $^{37)}$

Studies that have investigated verbal working memory using the $n$-back task and ERPs have consistently examined two ERP components; N2 and P3. N2, a negative peak observed over fronto-central sites at 180-300 ms after stimulus-onset, is known to reflect the retrieval of stored information $^{38)}$ or detection processing, in which a current stimulus is judged to be congruent or incongruent with the one presented $n$ trials earlier. ${ }^{39)}$ Daffner et al. ${ }^{39)}$ observed that N2 amplitude was larger when the current stimulus was incongruent than when it was congruent with the one presented $n$ trials earlier. Another ERP component explored in the context of verbal working memory is P3, which is a positive peak observed over centro-parietal sites at $\mathbf{3 0 0 - 5 0 0 ~ m s ~ a f t e r ~ s t i m u l u s - o n s e t . ~ I t ~ i s ~}$ known to reflect the categorization of stimuli, ${ }^{40)}$ the updating of memory, ${ }^{41,42)}$ or attentional allocation. ${ }^{43,44)}$ For example, McEvoy et al. ${ }^{45)}$ observed larger P3 amplitudes and shorter P3 latencies under a congruent than under an incongruent condition, and they suggested that $\mathrm{P} 3$ reflects the classification of congruent stimuli through the comparison of a current stimulus with the one presented $n$ trials earlier. Additionally, as there is no predetermined congruent stimulus in the $n$-back task, the stimulus presented in each trial should be updated to determine whether the stimulus is congruent with the one presented $n$ trials before. ${ }^{46,47)}$

Although working memory deficits in ADHD patients have been consistently reported, only a few studies have used ERPs to investigate working memory in ADHD patients. ${ }^{48,49)}$ Karayanidis et al. ${ }^{50)}$ investigated working memory in ADHD patients using verbal $n$-back task and ERPs, and found that ADHD patients exhibited sig- nificantly longer N2 latencies than did normal controls. They suggested that this result reflects impaired retrieval ability in ADHD patients. In addition, Keage et al. ${ }^{51)}$ found significantly smaller P3 amplitudes in ADHD patients compared with healthy controls, and suggested that these patients encounter difficulties in updating information and classifying congruent and incongruent stimuli. Recently, Kim et al $^{52)}$ studied working memory in college students with ADHD using ERPs and a delayed-match-to-sample task. They found reduced $\mathrm{P} 3$ amplitudes in ADHD patients, and suggested that ADHD patients have deficits in attentional allocation during encoding of working memory.

Given that several factors, including medication and the existence of comorbid disorders such as anxiety and mood disorders can affect performance on cognitive tasks, several studies have investigated nonclinical individuals with ADHD traits instead of ADHD patients. ${ }^{53)}$ Although only few studies have investigated verbal working memory in individuals with ADHD traits using the $n$-back task, these studies have reported that those with ADHD traits performed more poorly on this task than did normal controls. ${ }^{54)}$ Additionally, Cocchi et al. ${ }^{53)}$ observed abnormal connectivity among the frontal, temporal, and occipital lobes in individuals with ADHD traits, indicating possible neurofunctional abnormalities underlying deficits in working memory. To our knowledge, no ERP studies investigating verbal working memory in non-clinical individuals with ADHD traits have been conducted.

Therefore, we used ERPs and $n$-back task to investigate verbal working memory of non-clinical college students with ADHD traits. The primary objectives of this study were to investigate whether college students with ADHD traits showed deficits in verbal working memory and if so, whether these deficits were reflected in their ERPs. Based on previous findings, we expected that those with ADHD traits would show deficits in working memory and deficits in working memory would be reflected in prolonged N2 latencies and reduced P3 amplitudes.

\section{METHODS}

\section{Participants}

The present study included 57 right-handed college students recruited from a pool of 503 students and screened using the Adult ADHD Self-Report Scale (ASRS) ${ }^{55)}$ and the Conners' Adult ADHD Rating Scale (CAARS). ${ }^{56)}$ Students with scores $>4$ on part A of the ASRS, $>24$ total points on the ASRS, ${ }^{57)}$ and T scores $>65$ on the ADHD index of the CAARS ${ }^{56)}$ were included in ADHD-trait 
group. Among 503 students 72 students obtained $>4$ on part A and $>24$ total points on the ASRS, 56 students obtained T scores $>65$ on the ADHD index of the CAARS, and 43 students obtained $>4$ on part A of the ASRS, $>24$ total points on the ASRS and T scores $>65$ on the ADHD index of the CAARS. We excluded those with left-handedness (6), comorbidity (8), and the remaining 29 students ( 7 males and 22 females) were included in the ADHD-trait group. None of participants was previously diagnosed as ADHD. Those who with scores $<3$ on part A of the ASRS, $<16$ total points on the ASRS, and T scores $<37$ on the ADHD index of the CAARS were included in the normal control group ( $\mathrm{n}=28 ; 9$ males and 19 females).

The ASRS, a self-report questionnaire measuring adult ADHD, consists of 18 questions rated on a scale from 0 to 4 , with total scores ranging from 0 to 72 . Six items (part A) are particularly useful for evaluating ADHD symptoms, and those with scores $>4$ on part A are highly likely to be diagnosed with ADHD. Part A of the ASRS consists of 6 questions; 4 questions evaluating inattention and 2 questions evaluating hyperactivity/impulsivity. ${ }^{57)}$ Additionally, total scores $>24$ on the ASRS are associated with a high possibility of meeting criteria for ADHD. ${ }^{57)}$

The CAARS is a 66-item self-administered questionnaire for evaluating adult ADHD. Each item is rated on a scale from 0 to $3,{ }^{56)}$ and total scores range from 0 to 198.The CAARS consists of four factor-derived subscales (inattention/memory, hyperactivity/irritability, impulsivity/ emotional lability, and self-concept), two Diagnostic and Statistical Manual of Mental Disorders, fourth edition (DSM-IV) ADHD symptom subscales (inattentive symptoms and hyperactive-impulsive symptoms), and one ADHD index consisting of items that distinguish between ADHD patients and normal controls. Based on the norms obtained from a pool of North American adults, Conners et $a l^{56)}$ suggested that those with $\mathrm{T}$ scores $>65$ on the ADHD index of the CAARS are likely to be diagnosed with ADHD. Based on the CAARS ADHD index scores of 2,000 college students, we used cutoff $T$ scores of 65 (highest 10\%) and 37 (lowest 10\%) to define the ADHDtrait and control groups, respectively.

The Structured Clinical Interview for DSM-IV, non-patient version (SCID-NP) ${ }^{58)}$ was administered to ensure that participants did not have a history of psychiatric, medical, or neurological disorders or alcohol/drug abuse. Additionally, the Korean Wechsler Adult Intelligence Scale ${ }^{59)}$ was administered to measure participants' intelligence quotient (IQ). All participants were right-handed, and none was taking medication at the time of testing.
The participants were paid for their participation, and all provided written informed consent after receiving a complete description of the study. This study was approved by the Sungshin Women's University Institutional Bioethics Review Board (sswuirb-2013-003).

\section{The 2-Back Task}

The 2-back task was administered to measure verbal working memory. The task consists of a congruent condition, under which a current stimulus is the same as the one presented two trials earlier, and an incongruent condition, under which the current stimulus is not the same as the one presented two trials earlier. The numbers 1,2,3, and 4 were used as stimuli. A total of 360 trials ( 108 congruent trials, 252 incongruent trials) were randomly administered in two blocks. Participants were asked to respond as rapidly and accurately as possible to congruent stimuli and not to respond to incongruent stimuli.

Stimuli were presented for $500 \mathrm{~ms}$ at the center of the computer monitor using E-PRIME (Psychological Software Tools Inc., Sharpsburg, PA, USA), and each stimulus subtended vertical and horizontal visual angles of $3.5^{\circ}$ and $3.8^{\circ}$, respectively. Crosshairs (+) were displayed on the monitor for $1,500 \mathrm{~ms}$ as a fixation point, and the interstimulus interval was $2,500 \mathrm{~ms}$. Prior to the experimental session, a block of 20 trials was administered to ensure that the instructions were understood.

\section{Electrophysiological Recording Procedure}

Electroencephalographic (EEG) activity was recorded using a 64-channel HydroCel Geodesic Sensor Net connected to a 64-channel, high-input impedance amplifier (Net Amp 300; Electrical Geodesics, Eugene, OR, USA) in an electrically shielded and soundproofed experimental room. Each electrode was referenced to $\mathrm{Cz}$, and individual electrodes were adjusted until impedances were lower than $50 \mathrm{k} \Omega{ }^{60)}$

During the experiment, EEG activity was recorded continuously using a $0.1-100 \mathrm{~Hz}$ analog bandpass and a sampling rate of $250 \mathrm{~Hz}$. Following data collection, the EEG data were segmented into $1,000 \mathrm{~ms}$ epochs, including the $100 \mathrm{~ms}$ pre-stimulus baseline period. Epochs contaminated by artifacts, such as eye blinks and eye movements, were rejected prior to averaging (the threshold for artifact rejection was $\pm 70 \mu \mathrm{V}$ ). All data associated with congruent and incongruent conditions were averaged separately with an average-reference transformation, and the ERPs were digitally low-pass filtered at $30 \mathrm{~Hz}$. The mean numbers of trials included in the analysis were 275.54 (standard devi- 
Control group $(n=28)$
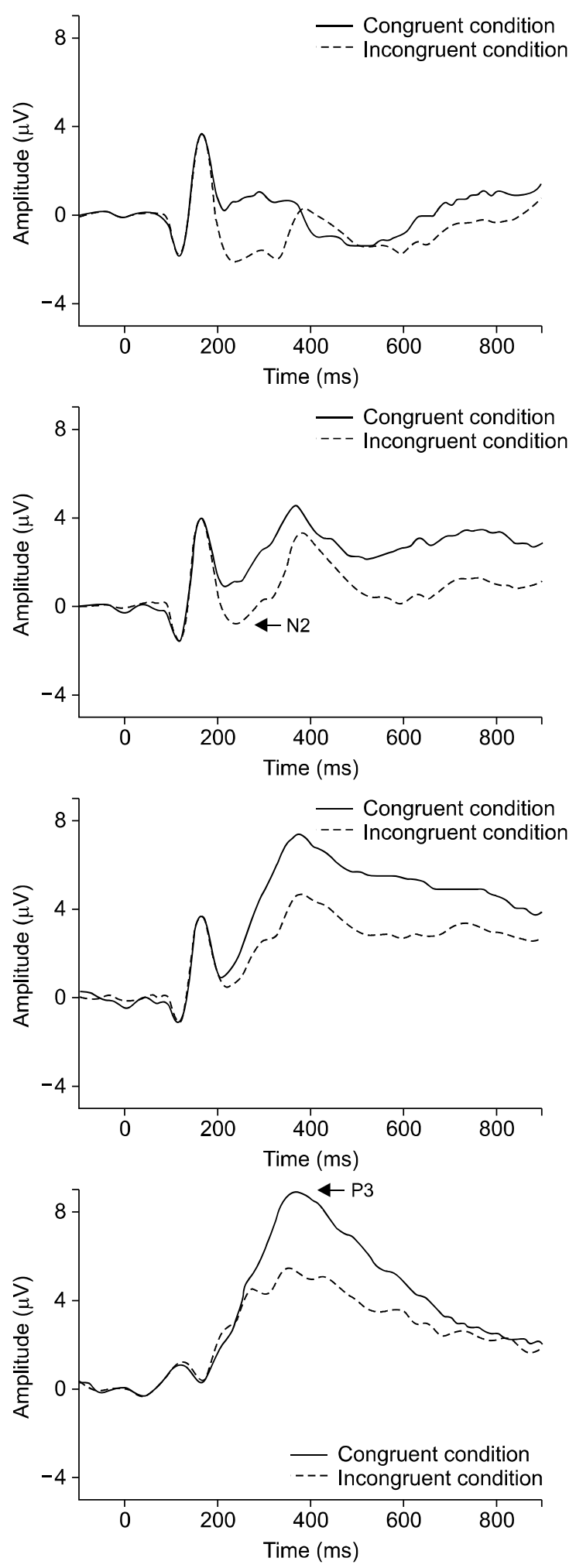

ADHD-trait group $(n=29)$
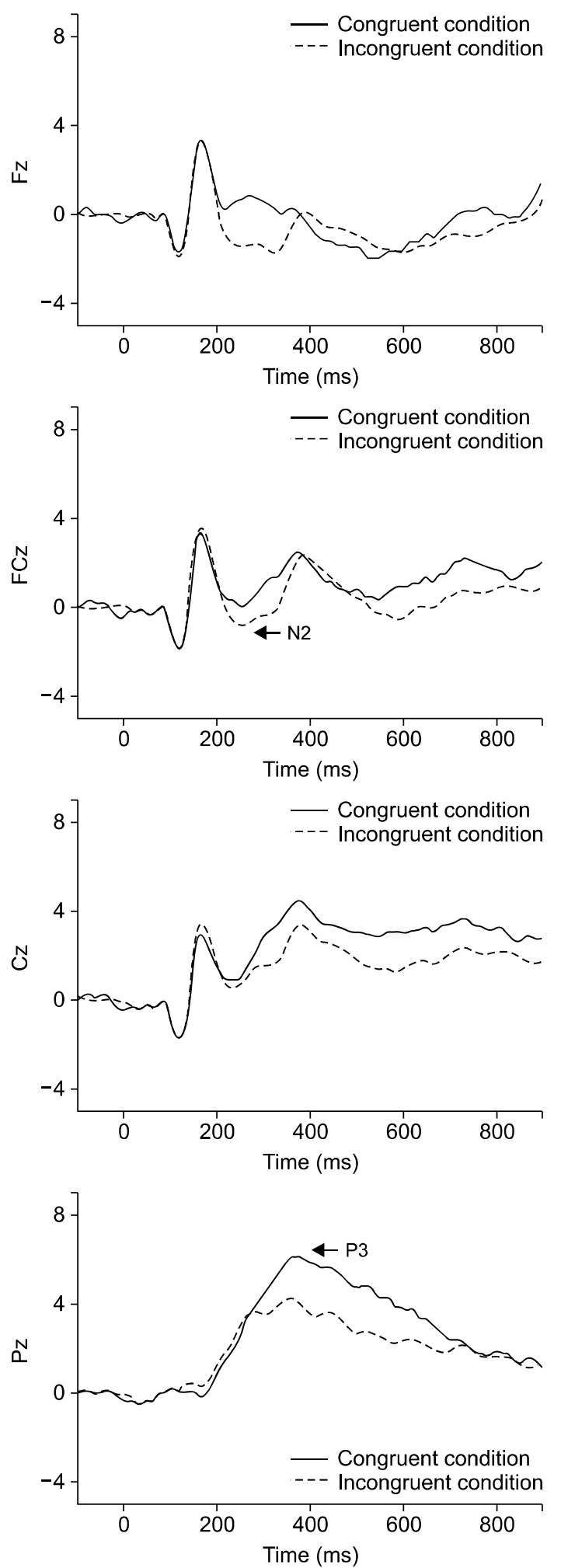

Fig. 1. The grand-averaged event-related potentials elicited by congruent and incongruent stimuli for normal control and attention-deficit/ hyperactivity disorder (ADHD)-trait groups. 
ation [SD], 59.43) and 249.07 (SD, 54.03) for the normal control and ADHD-trait groups, respectively. The two groups did not differ in terms of trials included in the analysis, $\mathrm{t}(55)=1.76$, not significant (ns).

\section{Statistical Analysis}

Based on the visual inspection of grand-averaged and individual ERP waveforms, two ERP components (N2 and P3) and time windows were determined. N2 was defined as the most negative peak observed at $180-300 \mathrm{~ms}$ after stimulus-onset, and $\mathrm{P} 3$ was defined as the most positive peak observed at 300-500 ms after stimulus-onset. N2 amplitudes and latencies were separately analyzed with a repeated-measures, mixed-design analysis of variance (ANOVA) with stimulus condition and electrode site (F3, Fz, F4, FC3, FCz, FC4, C3, Cz, C4) as within-subject factors and group as a between-subjects factor. Since the N2 was observed only on the fronto-central sites (Fig. 1), electrodes on the frontal and central sites were included in the statistical analysis. P3 amplitudes and latencies were separately analyzed with a repeated-measures, mixed-design ANOVA with stimulus condition and electrode site (F3, Fz, F4, FC3, FCz, FC4, C3, Cz, C4, P3, Pz, $\mathrm{P} 4$ ) as within-subject factors and group as a between-subjects factor. Greenhouse-Geisser corrections for sphericity violations were employed when appropriate, and the corrected $p$ values are reported. Variables showing significant main effects were further analyzed using a paired $t$-test or a one-way ANOVA.

Response times on the 2-back task were analyzed with one-way ANOVA, and accuracy was evaluated with repeated-measures, mixed-design ANOVA with stimulus condition (congruent and incongruent) as the within-subject factor and group (ADHD-trait and control) as the betweensubjects factor. Only correct responses were subjected to statistical analyses. Demographic characteristics and scores on the ASRS and CAARS were analyzed using independent-sample $t$-tests.

\section{RESULTS}

\section{Demographic Characteristics}

The ADHD-trait and control groups did not differ in age $(\mathrm{t}[55]=0.22$, ns), educational level $(\mathrm{t}[55]=-0.04$, ns), or total IQ scores (t $[55]=0.74, \mathrm{~ns})$. However, the ADHD-trait group had significantly higher part A scores $(\mathrm{t}[55]=$ $-20.21, p<0.001)$, total scores $(\mathrm{t}[55]=-28.11, p$ $<0.001)$ of the ASRS, and scores on the ADHD index of the CAARS-K $(\mathrm{t}[55]=-33.46, p<0.001)$ compared with the control group. The demographic characteristics and scores on the ASRS and CAARS of the two groups are presented in Table 1.

\section{The 2-Back Task}

\section{Behavioral results of the 2-back task}

Statistical analysis of response times under the congruent condition revealed that the ADHD-trait and control groups did not differ significantly $(\mathrm{F}[1,55]=0.29$, ns). In terms of accuracy, we found a main effect of stimulus condition $(\mathrm{F}[1,55]=93.80, p<0.001)$, with the incongruent stimuli eliciting significantly more errors compared with the congruent stimuli. We also found an interaction effect of stimulus condition by group $(\mathrm{F}[1,55]=7.04, p<0.05)$. The ADHD-trait group committed significantly more errors than did the control group under the congruent condition $(\mathrm{F}[1,55]=8.34, p<0.01)$, whereas the two groups did not significantly differ under the incongruent condition $(F[1,55]=2.60, n s)$. The mean response times and accuracy data for the two groups are presented in Table 2.

\section{ERP results on the 2-back task}

Figure 1 depicts the grand- averaged ERP waveforms elicited by congruent and incongruent stimuli at $\mathrm{Fz}, \mathrm{FCz}$, $\mathrm{CZ}$, and $\mathrm{Pz}$ for the two groups. Both groups showed the largest $\mathrm{N} 2$ and $\mathrm{P} 3$ amplitudes at $\mathrm{Fz}$ and $\mathrm{Pz}$, respectively. Figure 2 show the topographical distributions of electrical activity at the time when the maximum N2 and P3 ampli-

Table 1. Demographic characteristics in normal control and ADHDtrait groups

\begin{tabular}{lccc}
\hline & $\begin{array}{c}\text { Normal } \\
\text { control }(n=28)\end{array}$ & $\begin{array}{c}\text { ADHD-trait } \\
(n=29)\end{array}$ & $t$ \\
\hline Age (yr) & $21.61(2.08)$ & $21.48(2.15)$ & 0.22 \\
Gender (male:female) & $9: 19$ & $7: 22$ & \\
Educational level (yr) & $14.61(1.31)$ & $14.62(1.15)$ & -0.04 \\
IQ & $115.07(9.07)$ & $113.31(8.92)$ & 0.74 \\
ASRS & & & \\
$\quad$ Part A & $0.71(0.85)$ & $4.59(0.57)$ & $-20.21^{*}$ \\
$\quad$ Total points & $12.75(3.30)$ & $44.17(4.95)$ & $-28.11^{*}$ \\
CAARS & & & \\
Inattention/memory & $4.25(3.26)$ & $23.21(4.75)$ & $-17.51^{*}$ \\
$\quad$ Hyperactivity/irritability & $5.86(2.61)$ & $21.69(6.87)$ & $-11.42^{*}$ \\
Impulsivity/emotional & $2.82(2.20)$ & $22.69(4.55)$ & $-20.87^{*}$ \\
$\quad$ lability & & & \\
Self-concept & $3.21(2.44)$ & $13.21(3.95)$ & $-11.44^{*}$ \\
ADHD index & $3.61(1.75)$ & $23.66(2.66)$ & $-33.46^{*}$ \\
\hline
\end{tabular}

Values are presented as mean (standard deviation).

ADHD, attention-deficit/hyperactivity disorder; $1 Q$, intelligence quotient; ASRS, Adult ADHD Self-Report Scale; CAARS, Conners' Adult ADHD Rating Scale.

${ }^{*} p<0.001$. 
Table 2. Mean response times and accuracies on the 2-back task in normal control and ADHD-trait groups

\begin{tabular}{lccrlrl}
\hline & \multicolumn{2}{c}{ Normal control $(\mathrm{n}=28)$} & & \multicolumn{2}{c}{ ADHD-trait $(\mathrm{n}=29)$} \\
\cline { 2 - 2 } & Congruent & Incongruent & & Congruent & Incongruent \\
\hline Response time $(\mathrm{ms})$ & $425.41(80.23)$ & & & $436.88(80.01)$ & \\
Accuracy $(\%)$ & $89.29(8.26)$ & $98.10(1.95)$ & & $81.77(11.13)$ & $97.24(2.09)$ \\
\hline
\end{tabular}

Values are presented as mean (standard deviation).

ADHD, attention-deficit/hyperactivity disorder.

A

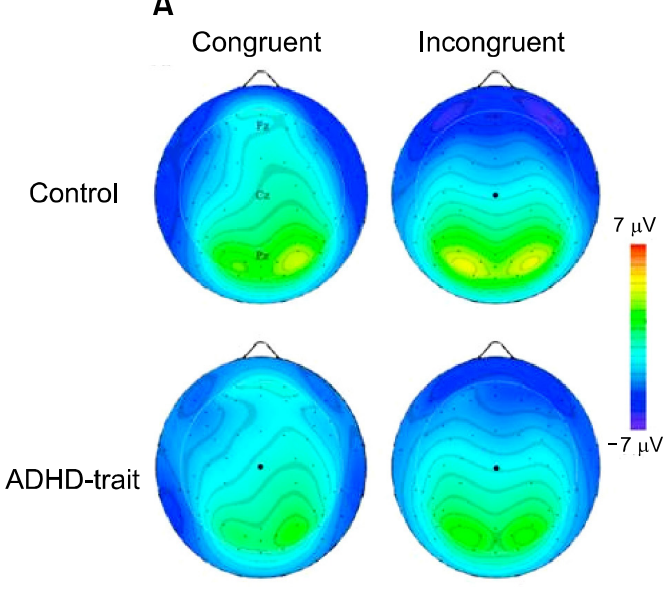

$230 \mathrm{~ms}$

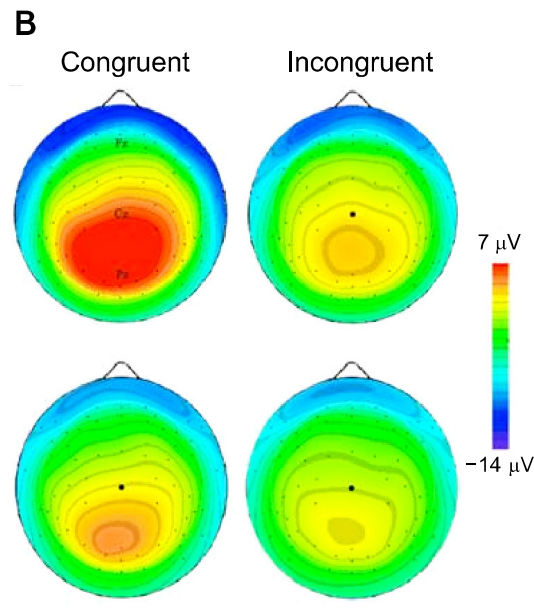

$380 \mathrm{~ms}$
Fig. 2. Topographical distributions of N2 (A) and P3 (B) elicited by congruent and incongruent stimuli for normal control and attentiondeficit/hyperactivity disorder (ADHD)trait groups. tudes, respectively, were observed. In terms of N2, both groups showed larger amplitudes in response to incongruent than to congruent stimuli, particularly at Fz. Both groups showed larger P3 amplitudes in response to congruent than to incongruent stimuli, particularly at $\mathrm{Pz}$, and the ADHD-trait group exhibited smaller P3 amplitudes compared with the normal control group.

Analysis of N2 amplitudes revealed main effects of stimulus condition $(\mathrm{F}[1,55]=12.41, p<0.05)$ and electrode site $(\mathrm{F}[8,440]=20.83, p<0.001)$. The incongruent stimuli elicited larger N2 amplitudes than did the congruent stimuli, and the largest amplitude was observed at Fz and smallest at C4. Additionally, an interaction effect of stimulus condition by electrode site was observed $(\mathrm{F}[8,440]=29.07, p<0.001)$. The incongruent stimuli elicited larger amplitudes than did the congruent stimuli at F3, Fz, F4, FCz and FC4, whereas the congruent stimuli elicited larger amplitudes than did incongruent stimuli at FC3 and C3. The amplitudes elicited by congruent and incongruent stimuli did not differ significantly at $\mathrm{Cz}$ and $\mathrm{C} 4$. No significant main effect of group $(\mathrm{F}[1,55]=0.79, \mathrm{~ns})$ and no interaction effect of electrode site by group $(\mathrm{F}[1,55]=$ $0.05, \mathrm{~ns}$ ) was observed. With respect to N2 latency, only a main effect of stimulus condition was observed $(\mathrm{F}[1,55]=$ $18.60, p<0.001$ ), with longer latencies in response to in- congruent than to congruent stimuli. No significant main effect of group $(\mathrm{F}[1,55]=1.16$, ns $)$ or electrode site $(\mathrm{F}[8,440]=1.88$, ns) was observed. The mean N2 amplitudes and latencies elicited by congruent and incongruent stimuli in the ADHD-trait and control groups are presented in Table 3.

With regard to $\mathrm{P} 3$ amplitude, main effects of stimulus condition $(\mathrm{F}[1,55]=62.17, p<0.001)$, electrode site $(\mathrm{F}[11,605]=76.43, p<0.001)$, and group $(\mathrm{F}[1,55]=16.93$, $p<0.001)$ were observed. Congruent stimuli elicited larger P3 amplitudes than did incongruent stimuli, and the largest amplitude was observed at $\mathrm{Pz}$, and the smallest at Fz. In terms of group, the ADHD-trait group showed significantly smaller P3 amplitudes than did the control group. Additionally, an interaction effect of stimulus condition by electrode site was observed $(\mathrm{F}[11,605]=16.01, p<0.001)$. Congruent stimuli elicited larger $\mathrm{P} 3$ amplitudes than did incongruent stimuli at F4, FCz, FC4, C3, Cz, C4, Pz, Pz, and $\mathrm{P} 4$, whereas the amplitudes elicited by congruent and incongruent stimuli did not differ significantly at F3, Fz, and FC3. In terms of P3 latencies, main effects of stimulus condition $(\mathrm{F}[1,55]=23.46, p<0.001)$ and electrode site $(\mathrm{F}[11,605]=3.03, p<0.05)$ were observed. Incongruent stimuli elicited longer P3 latencies than did congruent stimuli, and the shortest latency was observed at $\mathrm{Pz}$, and 
Table 3. Mean N2 amplitudes and latencies in normal control and ADHD-trait groups

\begin{tabular}{|c|c|c|c|c|c|}
\hline & \multirow{2}{*}{ Site } & \multicolumn{2}{|c|}{ Normal control $(n=28)$} & \multicolumn{2}{|c|}{ ADHD-trait $(n=29)$} \\
\hline & & Congruent & Incongruent & Congruent & Incongruent \\
\hline \multirow[t]{9}{*}{ Amplitude $(\mu \mathrm{V})$} & F3 (12) & $-1.65(2.25)$ & $-2.33(2.38)$ & $-1.28(1.93)$ & $-1.56(1.86)$ \\
\hline & $\mathrm{Fz}(6)$ & $-1.15(2.67)$ & $-2.96(2.79)$ & $-0.66(2.26)$ & $-2.29(2.24)$ \\
\hline & F4 (60) & -1.38 (3.09) & $-2.33(2.21)$ & $-0.73(2.12)$ & $-2.07(1.90)$ \\
\hline & FC3 (15) & $-1.23(1.69)$ & $-0.93(1.98)$ & $-0.99(1.79)$ & $-0.60(1.44)$ \\
\hline & $\mathrm{FCz}(4)$ & $-0.68(2.66)$ & $-1.80(2.80)$ & $-0.66(2.63)$ & $-1.33(2.49)$ \\
\hline & FC4 (53) & $-0.65(2.34)$ & $-1.14(2.37)$ & $0.01(1.83)$ & $-0.67(1.55)$ \\
\hline & C3 (20) & $-0.88(1.48)$ & $0.19(1.48)$ & $-0.57(1.72)$ & $0.21(1.34)$ \\
\hline & $\mathrm{Cz}$ & $-0.29(2.45)$ & $-0.44(2.62)$ & $-0.13(2.32)$ & $-0.15(2.17)$ \\
\hline & C4 (50) & $-0.34(1.98)$ & $-0.29(2.03)$ & $0.26(1.49)$ & $0.02(1.28)$ \\
\hline \multirow[t]{9}{*}{ Latency (ms) } & F3 (12) & $223.86(25.43)$ & 231.71 (24.32) & $224.41(22.56)$ & $239.45(27.35)$ \\
\hline & $\mathrm{Fz}(6)$ & $223.71(28.60)$ & $230.43(21.45)$ & $226.48(24.18)$ & $242.34(29.27)$ \\
\hline & F4 (60) & $222.71(26.02)$ & $231.86(20.15)$ & $225.79(25.36)$ & $239.17(25.13)$ \\
\hline & FC3 (15) & $224.43(27.16)$ & $229.86(26.27)$ & $225.10(26.64)$ & 240.41 (32.38) \\
\hline & $\mathrm{FCz}(4)$ & $226.86(28.76)$ & $232.29(24.92)$ & 225.93 (25.09) & $243.03(27.91)$ \\
\hline & FC4 (53) & $224.43(29.12)$ & $230.29(24.86)$ & $223.31(23.83)$ & $240.41(29.07)$ \\
\hline & C3 (20) & $223.57(25.86)$ & 226.57 (28.79) & $230.07(28.84)$ & $236.28(30.56)$ \\
\hline & $\mathrm{Cz}$ & $221.86(25.82)$ & $226.71(21.67)$ & $228.80(26.16)$ & $238.07(29.05)$ \\
\hline & C4 (50) & $220.43(28.97)$ & $221.57(24.52)$ & $226.90(24.91)$ & $235.17(30.07)$ \\
\hline
\end{tabular}

Values are presented as mean (standard deviation)

ADHD, attention-deficit/hyperactivity disorder.

Table 4. Mean P3 amplitudes and latencies in normal control and ADHD-trait groups

\begin{tabular}{|c|c|c|c|c|c|}
\hline & \multirow{2}{*}{ Site } & \multicolumn{2}{|c|}{ Normal control $(n=28)$} & \multicolumn{2}{|c|}{ ADHD-trait $(n=29)$} \\
\hline & & Congruent & Incongruent & Congruent & Incongruent \\
\hline \multirow[t]{12}{*}{ Amplitude $(\mu \mathrm{V})$} & F3 (12) & $1.82(2.75)$ & $2.03(2.46)$ & $1.26(1.83)$ & $1.29(1.76)$ \\
\hline & $F z(6)$ & $1.57(3.23)$ & $1.10(2.87)$ & $0.89(2.40)$ & $0.33(2.23)$ \\
\hline & F4 (60) & $2.78(3.16)$ & $2.26(2.21)$ & $2.05(2.27)$ & $0.93(1.65)$ \\
\hline & FC3 (15) & $4.01(2.13)$ & $3.75(2.19)$ & $2.67(1.37)$ & $2.67(1.77)$ \\
\hline & $\mathrm{FCz}(4)$ & $5.69(3.08)$ & $4.22(2.99)$ & $3.33(2.18)$ & $2.61(2.80)$ \\
\hline & FC4 (53) & $5.54(2.67)$ & $3.96(2.08)$ & $3.80(2.10)$ & $2.55(2.38)$ \\
\hline & C3 (20) & $5.58(2.21)$ & $4.32(1.60)$ & $3.67(1.84)$ & $3.31(1.57)$ \\
\hline & $\mathrm{Cz}$ & $8.60(3.24)$ & $5.69(2.61)$ & $5.14(2.33)$ & $3.73(2.03)$ \\
\hline & C4 (50) & $6.50(2.54)$ & $4.65(1.89)$ & $4.42(2.15)$ & $3.09(1.98)$ \\
\hline & P3 (28) & $7.53(2.51)$ & $5.02(1.24)$ & $5.06(2.58)$ & $3.75(1.57)$ \\
\hline & Pz (34) & $9.60(2.77)$ & $6.53(2.00)$ & $7.10(2.49)$ & $4.55(2.06)$ \\
\hline & P4 (42) & $7.21(3.13)$ & $5.32(2.15)$ & $4.78(1.61)$ & $3.40(1.63)$ \\
\hline \multirow[t]{12}{*}{ Latency (ms) } & F3 (12) & 367.00 (33.55) & $391.57(29.40)$ & $371.86(27.20)$ & 390.62 (25.33) \\
\hline & $\mathrm{Fz}(6)$ & $363.57(36.16)$ & $389.29(28.74)$ & $369.24(24.68)$ & 395.86 (22.89) \\
\hline & F4 (60) & $361.86(35.28)$ & $389.14(27.67)$ & $366.76(25.68)$ & $391.45(23.46)$ \\
\hline & FC3 (15) & $374.00(34.96)$ & $389.00(27.85)$ & $375.03(28.30)$ & $395.03(28.68)$ \\
\hline & $\mathrm{FCz}(4)$ & $370.29(34.09)$ & $387.14(28.44)$ & $370.07(25.22)$ & $392.83(29.15)$ \\
\hline & FC4 (53) & $369.43(37.59)$ & $387.00(27.19)$ & $367.86(25.26)$ & $392.00(31.96)$ \\
\hline & C3 (20) & $376.43(34.98)$ & $395.14(33.67)$ & $375.72(29.00)$ & $395.45(32.30)$ \\
\hline & $\mathrm{Cz}$ & $372.71(37.46)$ & $388.57(35.36)$ & $371.59(24.74)$ & $388.83(30.92)$ \\
\hline & C4 (50) & $373.14(38.50)$ & $389.57(33.65)$ & $373.66(24.60)$ & $392.21(32.22)$ \\
\hline & P3 (28) & $380.14(24.60)$ & $389.57(37.00)$ & 373.38 (24.59) & $384.83(38.19)$ \\
\hline & Pz (34) & $371.71(29.41)$ & $383.29(38.75)$ & $367.03(28.78)$ & $376.72(36.57)$ \\
\hline & P4 (42) & $372.57(31.68)$ & $385.28(39.10)$ & $366.76(30.39)$ & 378.34 (37.89) \\
\hline
\end{tabular}

Values are presented as mean (standard deviation).

ADHD, attention-deficit/hyperactivity disorder.

the longest one at $\mathrm{C} 3$. No significant difference between groups was observed in this regard $(\mathrm{F}[1,55]=0.01, \mathrm{~ns})$. The mean P3 amplitudes and latencies elicited by congruent and incongruent stimuli in the ADHD-trait and control groups are presented in Table 4. 


\section{DISCUSSION}

The present study used ERPs and a 2-back task to investigate whether college students with ADHD traits exhibited deficits in verbal working memory. Compared with the control group, the ADHD-trait group committed significantly more errors in response to congruent stimuli on the 2-back task; this result is consistent with previous studies with adult patients with ADHD or individuals with ADHD traits. For example, Schecklmann et al. ${ }^{61)}$ observed that adult ADHD patients performed significantly more poorly on the 2-back task compared with a normal control group. Ehlis et al. ${ }^{25)}$ also found that ADHD patients committed more errors on the 2-back task than did a control group. Additionally, Engelhardt et al. ${ }^{54)}$ reported that adults with ADHD traits exhibited poorer performances on the $n$-back task compared with control group. Taken together with those of previous studies, the present results indicate that individuals with ADHD traits exhibit difficulties related to verbal working memory.

The ADHD-trait and control groups did not differ with respect to $\mathrm{N} 2$ amplitudes and latencies, and both groups exhibited significantly larger N2 amplitudes and longer latencies in response to incongruent than to congruent stimuli. N2 is known to reflect the processing involved in detecting whether a current stimulus is congruent or incongruent with one presented $n$ trials earlier, ${ }^{39)}$ and the present results support this functional significance of N2. Unlike the present results, previous studies have reported that ADHD patients exhibited significantly longer N2 latencies than did normal controls. ${ }^{51,62)}$ These inconsistent findings may be related to methodological differences, such as the characteristics of participants, particularly the ratio of male to female participants in the sample used in this study. For example, Valera et $a l .{ }^{36)}$ investigated neural activation while adult patients with ADHD were performing the 2-back task and found gender differences in neural activation. Male ADHD patients exhibited reduced activation in the right frontal and subcortical areas compared with normal male participants, whereas no differences in neural activation between female ADHD patients and normal female participants were observed. Previous studies that observed delayed N2 latencies in ADHD patients were four times more likely to use male than female participants. In contrast, in the present study, the ratio of female to male subjects was approximately 3 to 1 , which may have contributed to the lack of differences in the N2 latencies between the ADHD-trait and control groups.

The ADHD-trait group showed significantly smaller P3 amplitudes compared with the control group, which is consistent with previous studies with adult ADHD patients. For example, Keage et al. ${ }^{51)}$ observed significantly reduced P3 amplitudes at the central and parietal areas of ADHD patients relative to those of normal controls, and the authors suggested that reduced P3 amplitude reflected impaired ability to accept new information (i.e., updating processing) in ADHD patients. Additionally, Kim et al. ${ }^{52)}$ observed reduced $\mathrm{P} 3$ amplitudes at the posterior temporal site and suggested that this result indicated inefficient attentional allocation by ADHD patients.

The functional significance of the P3 amplitude in working memory tasks is not fully understood. Some authors have suggested that the P3 amplitude reflects attentional capacity related to the classification of task-relevant stimuli, ${ }^{40)}$ whereas others have suggested that the P3 amplitude reflects the updating of the current contents of working memory. ${ }^{41,42)}$ Still others have suggested that the P3 amplitude reflects the effort to allocate attention. ${ }^{43,44)}$ Therefore, the reduced P3 amplitudes in individuals with ADHD traits observed in the present study suggest that these individuals have difficulties with working memory, possibly due to difficulties in memory updating or attentional allocation.

The present study has several limitations that should be addressed in future research. First, the inclusion of a relatively small number of participants limits the generalizability of the findings. Second, due to the small number of participants we could not investigate the verbal working memory of individuals with ADHD traits according to subtype (inattention, hyperactivity and mixed) or gender. Third, as structural and functional abnormalities in ADHD patients have been reported, an analysis of the sources of N2 and P3 and the relationship between source activation and behavioral performance on the 2-back task among individuals with ADHD traits would provide valuable information regarding the neural mechanisms underlying deficits in verbal working among these individuals.

In conclusion, college students with ADHD traits committed significantly more errors in response to congruent stimuli on the 2-back task and exhibited smaller P3 amplitudes relative to controls. These findings suggest that individuals with ADHD traits exhibit deficits in verbal working memory, possibly due to difficulties in memory updating or attentional allocation. In addition, the present results suggest that working memory deficits are present in non-clinical individuals with ADHD traits as well as ADHD patients, and that reduced P3 amplitudes may serve as a biological marker of or a risk factor for ADHD. 


\section{Acknowledgments}

This work was supported by the Sungshin Women's University Research Grant of 2014.

\section{REFERENCES}

1. American Psychiatric Association. Diagnostic and statistical manual of mental disorders. 5th ed. Washington, DC:American Psychiatric Association;2013.

2. Barkley RA, Fischer M, Edelbrock CS, Smallish L. The adolescent outcome of hyperactive children diagnosed by research criteria: I. An 8-year prospective follow-up study. J Am Acad Child Adolesc Psychiatry 1990;29:546-557.

3. Biederman J. Attention-deficit/hyperactivity disorder: a selective overview. Biol Psychiatry 2005;57:1215-1220.

4. Simon V, Czobor P, Bálint S, Mészáros A, Bitter I. Prevalence and correlates of adult attention-deficit hyperactivity disorder: meta-analysis. Br J Psychiatry 2009;194:204-211.

5. Hervey AS, Epstein JN, Curry JF. Neuropsychology of adults with attention-deficit/hyperactivity disorder: a metaanalytic review. Neuropsychology 2004;18:485-503.

6. Rapport LJ, Van Voorhis A, Tzelepis A, Friedman SR. Executive functioning in adult attention-deficit hyperactivity disorder. Clin Neuropsychol 2001;15:479-491.

7. Marchetta ND, Hurks PP, Krabbendam L, Jolles J. Interference control, working memory, concept shifting, and verbal fluency in adults with attention-deficit/hyperactivity disorder (ADHD). Neuropsychology 2008;22:74-84.

8. Martinussen R, Hayden J, Hogg-Johnson S, Tannock R. A meta-analysis of working memory impairments in children with attention-deficit/hyperactivity disorder. J Am Acad Child Adolesc Psychiatry 2005;44:377-384.

9. Murphy KR, Barkley RA, Bush T. Executive functioning and olfactory identification in young adults with attention deficithyperactivity disorder. Neuropsychology 2001;15:211-220.

10. Rohlf H, Jucksch V, Gawrilow C, Huss M, Hein J, Lehmkuhl U, et al. Set shifting and working memory in adults with attention-deficit/hyperactivity disorder. J Neural Transm 2012;119:95-106.

11. Schweitzer JB, Hanford RB, Medoff DR. Working memory deficits in adults with ADHD: is there evidence for subtype differences? Behav Brain Funct 2006;2:43.

12. Stearns CL, Dunham M, McIntosh D, Dean RS. Attention deficit/hyperactivity disorder and working memory in clinically referred adults. Int J Neurosci 2004;114:273-287.

13. Baddeley $\mathrm{AD}$, Hitch G. Working memory. In: Bower G, editor. The psychology of learning and motivation. Vol. 8. New York:Academic Press;1974. p.47-89.

14. Engle RW, Kane MJ, Tuholski SW. Individual differences in working memory capacity and what they tell us about controlled attention, general fluid intelligence, and functions of the prefrontal cortex. In: Mivake A, Shah P, editors. Models of working memory: Mechanisms of active maintenance and executive control. New York:Cambridge University Press; 1999. p.102-134.

15. Mariani MA, Barkley RA. Neuropsychological and academic functioning in preschool boys with attention deficit hyperactivity disorder. Dev Neuropsychol 1997;13:111-129.

16. Gathercole SE, Alloway TP, Kirkwood HJ, Elliott JG, Holmes J, Hilton KA. Attentional and executive function behaviours in children with poor working memory. Learn Individ Differ 2008;18:214-223.

17. Klingberg T, Fernell E, Olesen PJ, Johnson M, Gustafsson
$\mathrm{P}$, Dahlström K, et al. Computerized training of working memory in children with ADHD--a randomized, controlled trial. J Am Acad Child Adolesc Psychiatry 2005;44:177-186.

18. Kofler MJ, Rapport MD, Bolden J, Sarver DE, Raiker JS. ADHD and working memory: the impact of central executive deficits and exceeding storage/rehearsal capacity on observed inattentive behavior. J Abnorm Child Psychol 2010;38:149-161.

19. Gevins A, Cutillo B. Spatiotemporal dynamics of component processes in human working memory. Electroencephalogr Clin Neurophysiol 1993;87:128-143.

20. Owen AM, McMillan KM, Laird AR, Bullmore E. N-back working memory paradigm: a meta-analysis of normative functional neuroimaging studies. Hum Brain Mapp 2005;25: 46-59.

21. McElree B. Working memory and focal attention. J Exp Psychol Learn Mem Cogn 2001;27:817-835.

22. Meegan DV, Purc-Stephenson R, Honsberger MJ, Topan M. Task analysis complements neuroimaging: an example from working memory research. Neuroimage 2004;21:1026-1036.

23. Smith ME, McEvoy LK, Gevins A. Neurophysiological indices of strategy development and skill acquisition. Brain Res Cogn Brain Res 1999;7:389-404.

24. Bayerl M, Dielentheis TF, Vucurevic G, Gesierich T, Vogel $\mathrm{F}$, Fehr C, et al. Disturbed brain activation during a working memory task in drug-naive adult patients with ADHD. Neuroreport 2010;21:442-446.

25. Ehlis AC, Bähne CG, Jacob CP, Herrmann MJ, Fallgatter AJ. Reduced lateral prefrontal activation in adult patients with attention-deficit/hyperactivity disorder (ADHD) during a working memory task: a functional near-infrared spectroscopy (fNIRS) study. J Psychiatr Res 2008;42:1060-1067.

26. Awh E, Jonides J, Smith EE, Schumacher EH, Koeppe RA, Katz S. Dissociation of storage and rehearsal in verbal working memory: Evidence from positron emission tomography. Psychol Sci 1996;7:25-31.

27. Cohen JD, Perlstein WM, Braver TS, Nystrom LE, Noll DC, Jonides J, et al. Temporal dynamics of brain activation during a working memory task. Nature 1997;386:604-608.

28. Jansma JM, Ramsey NF, Coppola R, Kahn RS. Specific versus nonspecific brain activity in a parametric $N$-back task. Neuroimage 2000;12:688-697.

29. Smith EE, Jonides J. Working memory: a view from neuroimaging. Cogn Psychol 1997;33:5-42.

30. Cabeza R, Nyberg L. Imaging cognition II: An empirical review of 275 PET and fMRI studies. J Cogn Neurosci 2000;12:1-47.

31. D'Esposito M, Aguirre GK, Zarahn E, Ballard D, Shin RK, Lease J. Functional MRI studies of spatial and nonspatial working memory. Brain Res Cogn Brain Res 1998;7:1-13.

32. Fiez JA, Raife EA, Balota DA, Schwarz JP, Raichle ME Petersen SE. A positron emission tomography study of the short-term maintenance of verbal information. J Neurosci 1996; 16:808-822.

33. Wager TD, Smith EE. Neuroimaging studies of working memory: a meta-analysis. Cogn Affect Behav Neurosci 2003:3:255-274.

34. Schweitzer JB, Faber TL, Grafton ST, Tune LE, Hoffman JM, Kilts CD. Alterations in the functional anatomy of working memory in adult attention deficit hyperactivity disorder. Am J Psychiatry 2000;157:278-280.

35. Valera EM, Faraone SV, Biederman J, Poldrack RA, Seidman LJ. Functional neuroanatomy of working memory in adults with attention-deficit/hyperactivity disorder. Biol Psychiatry 2005;57:439-447.

36. Valera EM, Brown A, Biederman J, Faraone SV, Makris N, 
Monuteaux MC, et al. Sex differences in the functional neuroanatomy of working memory in adults with ADHD. Am J Psychiatry 2010;167:86-94.

37. Luck SJ. An introduction to the event-related potential technique. Cambridge, MA:MIT press;2005. p.21-25.

38. Missonnier P, Leonards U, Gold G, Palix J, Ibáñez V, Giannakopoulos P. A new electrophysiological index for working memory load in humans. Neuroreport 2003;14: 1451-1455.

39. Daffner KR, Chong H, Sun X, Tarbi EC, Riis JL, McGinnis $\mathrm{SM}$, et al. Mechanisms underlying age- and performancerelated differences in working memory. $J$ Cogn Neurosci 2011;23:1298-1314.

40. Kok A. On the utility of P3 amplitude as a measure of processing capacity. Psychophysiology 2001;38:557-577.

41. Donchin E. Presidential address, 1980. Surprise!...Surprise? Psychophysiology 1981;18:493-513.

42. Donchin E, Coles MGH. Is the P300 component a manifestation of context updating? Behav Brain Sci 1988;11:357-374.

43. Ford JM, White P, Lim KO, Pfefferbaum A. Schizophrenics have fewer and smaller P300s: a single-trial analysis. Biol Psychiatry 1994;35:96-103.

44. Polich J. Updating P300: an integrative theory of P3a and P3b. Clin Neurophysiol 2007;118:2128-2148.

45. McEvoy LK, Smith ME, Gevins A. Dynamic cortical networks of verbal and spatial working memory: effects of memory load and task practice. Cereb Cortex 1998;8:563-574.

46. Gevins A, Smith ME. Neurophysiological measures of working memory and individual differences in cognitive ability and cognitive style. Cereb Cortex 2000;10:829-839.

47. Wild-Wall N, Falkenstein M, Gajewski PD. Age-related differences in working memory performance in a 2-back task. Front Psychol 2011;2:186.

48. Barry RJ, Johnstone SJ, Clarke AR. A review of electrophysiology in attention-deficit/hyperactivity disorder: II. Eventrelated potentials. Clin Neurophysiol 2003;114:184-198.

49. Johnstone SJ, Barry RJ, Clarke AR. Ten years on: a follow-up review of ERP research in attention-deficit/ hyperactivity disorder. Clin Neurophysiol 2013;124:644-657.

50. Karayanidis F, Robaey P, Bourassa M, De Koning D, Geoffroy G, Pelletier G. ERP differences in visual attention processing between attention-deficit hyperactivity disorder and control boys in the absence of performance differences. Psychophysiology 2000;37:319-333.
51. Keage HA, Clark CR, Hermens DF, Williams LM, Kohn MR, Clarke S, et al. ERP indices of working memory updating in $A D / H D$ : differential aspects of development, subtype, and medication. J Clin Neurophysiol 2008;25:32-41.

52. Kim S, Liu Z, Glizer D, Tannock R, Woltering S. Adult $A D H D$ and working memory: neural evidence of impaired encoding. Clin Neurophysiol 2014;125:1596-1603.

53. Cocchi L, Bramati IE, Zalesky A, Furukawa E, Fontenelle $\mathrm{LF}$, Moll J, et al. Altered functional brain connectivity in a non-clinical sample of young adults with attention-deficit/ hyperactivity disorder. J Neurosci 2012;32:17753-17761.

54. Engelhardt PE, Nigg JT, Carr LA, Ferreira F. Cognitive inhibition and working memory in attention-deficit/hyperactivity disorder. J Abnorm Psychol 2008;117:591-605.

55. Adler LA, Kessler RC, Spencer T. Adult ADHD self-report scale-v1. 1 (ASRS-v1. 1) symptom checklist. New York, NY:World Health Organization;2003.

56. Conners CK, Erhardt D, Sparrow EP. Conners' adult ADHD rating scales: technical manual. New York:Multi-Health Systems; 1999.

57. Kessler RC, Adler L, Ames M, Demler O, Faraone S, Hiripi $\mathrm{E}$, et al. The World Health Organization Adult ADHD Self-Report Scale (ASRS): a short screening scale for use in the general population. Psychol Med 2005;35:245-256.

58. First MB, Gibbon M, Spitzer RL, Williams JBW. User's guide for the structured clinical interview for DSM-IV Axis I disorders: SCID-I - Research Version. New York:Biometrics Research Department, New York State Psychiatric Institute; 1996.

59. Yum TH, Park YS, Oh KJ, Kim JG, Lee YH. Manual of the Korean-Wechsler Adult Intelligence Scale. Seoul:Korean Guidance Press; 1992.

60. Tucker DM. Spatial sampling of head electrical fields: the geodesic sensor net. Electroencephalogr Clin Neurophysiol 1993;87:154-163.

61. Schecklmann M, Ehlis AC, Plichta MM, Dresler T, Heine $\mathrm{M}$, Boreatti-Hümmer A, et al. Working memory and response inhibition as one integral phenotype of adult ADHD? A behavioral and imaging correlational investigation. $J$ Atten Disord 2013;17:470-482.

62. Missonnier P, Hasler R, Perroud N, Herrmann FR, Millet $\mathrm{P}$, Richiardi $\mathrm{J}$, et al. EEG anomalies in adult ADHD subjects performing a working memory task. Neuroscience 2013;241: 135-146. 